\title{
Proto-Acting as a New Concept: Personal Mimicry and the Origins of Role Playing
}

\section{Steven Brown}

Department of Psychology, Neuroscience \& Behaviour, McMaster University, Hamilton, ON L8S 4K1, Canada; stebro@mcmaster.ca

Received: 4 May 2017; Accepted: 16 June 2017; Published: 20 June 2017

\begin{abstract}
Proto-acting is introduced here as a new concept that refers to a set of processes that are intermediate between everyday role playing (in the Erving Goffman sense) and dramatic acting. Its most characteristic process is the voluntary act of personal mimicry, which can occur in everyday contexts, such as quoting someone during conversation, or in performance contexts, such as impressionism. Proto-acting involves character portrayal, but on a much simpler and more transient scale than in dramatic acting, where a person may portray a character for an extended period of time during a stage performance. For example, this might involve impersonating the characters while reading a bedtime story to a child, or children themselves portraying characters while engaging in pretend play. Other key features of proto-acting are that it tends to be driven by gesture, have minimal scripting, and involve short bouts of alternation between the self and characters. Proto-acting, as based on personal mimicry, might provide a cognitive foundation for dramatic acting in human development. Moreover, proto-acting itself might be underlain evolutionarily by the process of pantomime, which often involves intentional mimicry of the actions of other people. Hence, the proto-acting concept is able to shed light on processes relevant to cognition, development, the performing arts, and human evolution.
\end{abstract}

Keywords: proto-acting; acting; role playing; pantomime; mimicry; language; theatre; gesture; imitation

\section{Introduction}

Acting is the process of portraying a character during a dramatic performance, such as when a man portrays Romeo during a stage production of Shakespeare's play Romeo and Juliet. Acting is generally a specialized skill acquired by a professional caste of dramatic actors, who spend years developing the craft of character portrayal, either in acting schools or through apprenticeship with mentors (Schechner 2013). Sociologists in the 20th century, using dramatic acting as a model, developed the perspective that everyday social behavior is akin to a form of acting. This "dramaturgical" model of social life (Goffman 1959; Shulman 2017) argues that people have multiple "personas" of themselves, and that they recruit these different personas-i.e., they act out different roles-in different social contexts. In contrast to dramatic acting, people in everyday contexts do not typically portray characters other than themselves; exceptions include criminal deception and situations of mental illness. Rather, they portray diverse variants of themselves, their personas. For example, the role of "parent" is a dominant persona played out in a parenting context, whereas the role of "customer" is often a more submissive persona played out in a consumer context. The dramaturgical perspective argues that nobody has a single, fixed self, but that one's self varies as a function of social situations and interaction partners (Shulman 2017).

While the dramaturgical perspective in sociology has shed much light on the context-dependence of human social behavior, there are significant differences between everyday role playing and dramatic 
acting. Professional actors almost always portray characters other than themselves, whereas everyday people rarely do. Professional actors portray characters during stage performances of dramatic works, whereas everyday people play roles in quotidian social situations. Professional actors generally speak lines that are scripted by authors (often long dead), whereas everyday people improvise their lines during conversations.

The main proposal of this article is that everyday role playing and dramatic acting comprise two ends of a spectrum, and that critical intermediate processes sit in between them. I will refer to these intermediate processes using the neologism proto-acting (Figure 1), and will attempt to provide a characterization of its nature in this article. Proto-acting is similar to dramatic acting and different from everyday role playing in that it involves character portrayal. However, this portrayal can occur in everyday contexts, as well as in stage performance. In fact, the contexts for proto-acting are quite diverse, as will be described in detail below. In the final section of the article, I will attempt to provide an evolutionary account of proto-acting and will argue that proto-acting evolved from the process of pantomime, which I will consider as the precursor to the phenomena of personal mimicry, role playing, and acting.

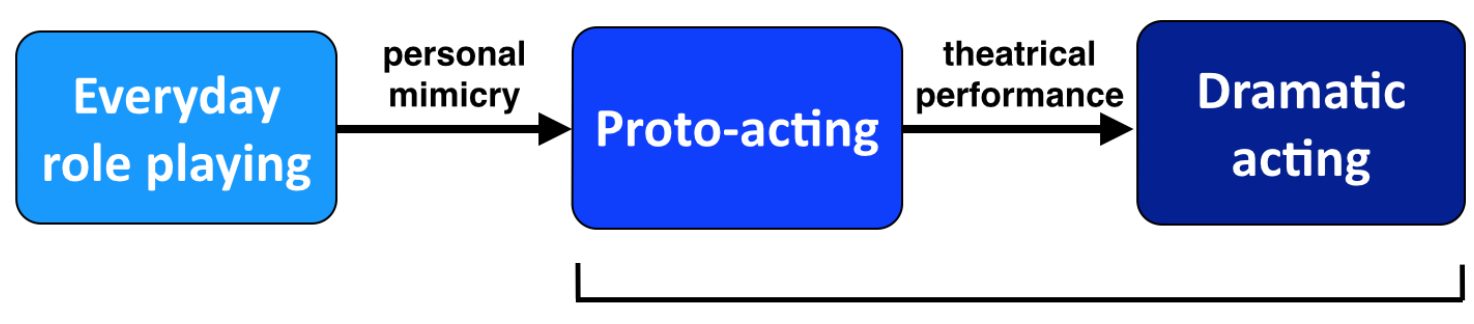

SELF CHARACTER

Figure 1. Proto-acting as an intermediate function between everyday role playing and dramatic acting. Whereas everyday role playing involves variants of the self, both proto-acting and dramatic acting involve character portrayal.

\section{Features of Proto-Acting}

In this section, I will attempt to flesh out the concept of proto-acting and describe its characteristic features compared to both everyday role playing and dramatic acting. Table 1 serves as a guide for my discussion. As will be clear from the ensuing discussion, I propose the concept of proto-acting as an umbrella term for a very diverse set of phenomena that have, thus far, not been related to one another in any formal manner. Hence, the major goal of the article is to provide a unification for a large number of behaviors-both everyday behaviors and public performances-that involve some degree of character portrayal, even when this occurs very transiently. This has applications not only to cognitive and sociological models of human behavior, but to numerous forms of the performing arts outside of standard dramatic performance.

Whereas everyday role playing is generally about the self, proto-acting is about the "other", just like dramatic acting. It can be thought of as the most fundamental form of character portrayal in human life. Proto-acting is a process of personal mimicry, and the characters being portrayed are very often familiar people, such as members of one's social circle or contemporary celebrities, like media figures or politicians. Whereas dramatic character portrayal can be accomplished through either gestural or mentalistic means (Wilshire 1982; Konijn 2000; Zarrilli 2009; Kemp 2012; Schechner 2013), proto-acting is firmly focused on the gestural features of the character, since it is principally a form of mimicry. By mimicry I am referring to the voluntary and intentional process of portraying someone during an act of communication, rather than to the involuntary gestural-imitation processes that underlie so-called chameleon effects during conversation, such as when someone unconsciously scratches their head immediately after their conversation partner does (Chartrand and Bargh 1999). 
Table 1. Proto-acting in comparison to everyday role playing and dramatic acting.

\begin{tabular}{|c|c|c|c|}
\hline & Everyday Role Playing & Proto-Acting & Dramatic Acting \\
\hline Self or Other & self & other & other \\
\hline Personal Mimicry & no & $\begin{array}{l}\text { yes, based on } \\
\text { personal mimicry }\end{array}$ & yes, if gestural acting \\
\hline Characters & personas of the self & familiar people & dramatic characters \\
\hline Gestural or Mentalistic & $\begin{array}{c}\text { more mentalistic } \\
\text { than gestural }\end{array}$ & gestural & $\begin{array}{l}\text { gestural or } \\
\text { mentalistic }\end{array}$ \\
\hline Role Changes & infrequent role changes & frequent role changes & $\begin{array}{l}\text { few or no } \\
\text { role changes }\end{array}$ \\
\hline Alternation with Self & $\begin{array}{l}\text { only self, hence } \\
\text { no alternation }\end{array}$ & $\begin{array}{l}\text { self/character } \\
\text { alternation }\end{array}$ & $\begin{array}{l}\text { no self/character } \\
\text { alternation }\end{array}$ \\
\hline Auto-Dialogue & no & yes & no \\
\hline Context & $\begin{array}{l}\text { usually everyday } \\
\text { contexts }\end{array}$ & $\begin{array}{l}\text { everyday contexts } \\
\text { or performance }\end{array}$ & performance \\
\hline Bout Length & short or long & generally short & long \\
\hline Script & unscripted & unscripted or scripted & usually scripted \\
\hline Use of Props & minimal use of props & some use of props & frequent use of props \\
\hline
\end{tabular}

Role changes can be frequent in proto-acting. For example, if a person describes a recent conversation with two friends by using a serial process of quotation ("And he said 'I'm not going to that party', and she was like 'Oh yes you are', and so I got frustrated and said 'Would you two please make up your mind! Coming or going?'"'), that person may alternate rapidly between the portrayed characters, as well as between the characters and himself. I label this process as "auto-dialogue" in Table 1. By this I mean a dialogue conveyed by a single person, as in the example just mentioned here where one person, through serial quotation, speaks the lines of two other people in addition to himself. Mimicry during conversation might even be done for entertainment purposes by invoking the features of a well-known person. For example, in responding to a question about how my day went, I might say "It started out pretty well but ended in a very very bad way" where the phrase "very very bad" was uttered using the voice and gestures of Donald Trump, followed by a return to my regular voice.

The comparable situation of role change for everyday role playing would require that a person switch from one social scenario to another. This would tend to happen on a much slower time scale than the example just mentioned of the conveyance of a conversation using serial quotation. The comparable situation for dramatic role playing is that an actor portrays a single character for an extended period of time and does not come out of character (at least not to the audience) until a performance is over. In other words, there is no alternation between the character and oneself during a performance, which contrasts strongly with proto-acting forms like impressionism or ventriloquism (discussed below), in which there is frequent alternation between oneself and different characters.

\section{Contexts and Forms}

What are the contexts and principal forms of proto-acting? Whereas everyday role playing occurs in quotidian contexts, and dramatic acting occurs in the context of public performance, proto-acting straddles the divide between everyday situations and performance contexts. Figure 2 presents a list of some of the major forms of proto-acting, divided into everyday, performance, and religious forms. The principal everyday form of proto-acting is storytelling. This includes the already-mentioned forms of serial quotation (auto-dialogue) and gestural mimicry that occur quite routinely during conversation. Another form occurs when adults read fairy tales to children. It is quite common for a person to impersonate the characters during moments of dialogue or self-thought. Given that 
most stories have multiple characters who engage in dialogue with one another, proto-acting during story reading requires rapid and abrupt alternation between contrastive characters, a phenomenon with no counterpart in dramatic acting but that shows similarities to serial quotation in conversation. A well-known example is the following passage from Goldilocks and the Three Bears:

"Somebody's been eating my porridge," said Father Bear.

"Somebody's been eating MY porridge," said Mother Bear.

"Somebody's been eating MY porridge and it's all gone!" said Baby Bear.

An engaging storyteller would use a low-pitched voice for Father Bear, a mid-pitched voice for Mother Bear, and a high-pitched voice for Baby Bear. The same thing would occur if a person were dressed as the character of Father Bear at a Halloween party. The person might speak in his normal conversational voice during much of the party, but then break into the Father Bear voice from time to time as a form of proto-acting that accompanies the prop of the costume.

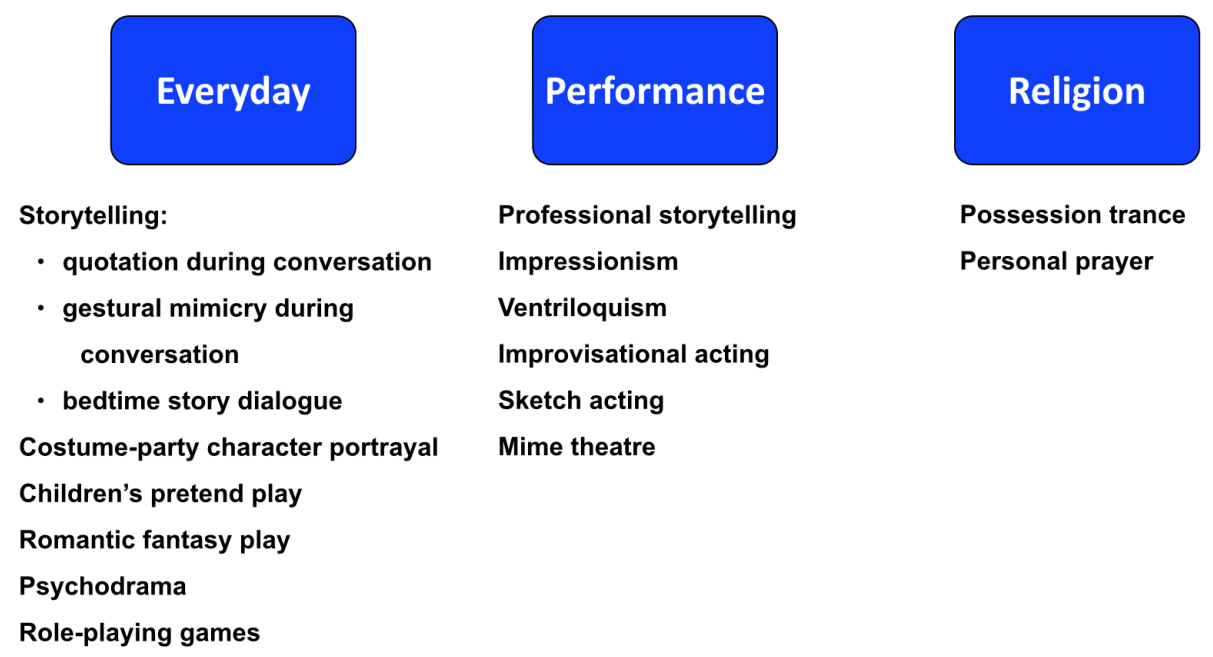

Figure 2. Common forms of proto-acting. The forms are divided into everyday, performance, and religion-related categories.

Next, Figure 2 lists pretend play in children as another everyday form of proto-acting (Walton 1990; Lillard 1996; Harris 2000), which I see as the ontogenetic precursor of improvisational acting in adults, mentioned below as a performance form of proto-acting. Unlike proto-acting forms such as quotation in conversation, the character portrayal that occurs during pretend play can span an extended period of time, where each child makes a commitment to a single character. Props are commonly involved in pretend play. One interesting prop that I would like to highlight is the use of a doll or stuffed animal as the child's interaction partner. While pretend play often involves two children engaged in a dialogue, it can also involve one child interacting with an inanimate object (or a group of them) which becomes personified by the child, for example a teddy bear who is the guest at a young girl's tea party. This form of proto-acting not only involves role playing (e.g., the girl playing the role of the hostess of the party), but a process of "animation" and/or "personification" of inanimate objects. This latter might serve as a developmental precursor of religious ideas about the animacy and agency of idols and other inanimate objects (Harvey 2006). Hence, in parallel with role playing per se, we see personification as another component of some forms of proto-acting. Adults too can engage in pretend play, for example fantasy role playing among romantic partners (e.g., husband as delivery man, or wife as naughty nurse). Another everyday context for proto-acting would be the uses of role playing in therapeutic contexts, most notably psychodrama and sociodrama (D'Amato and Dean 1988; Kipper and Ritchie 2003). 
The last thing I list in this part of Figure 2 is a recent surge of interest in role-playing-based games, including board games, live action role-play (LARP) games, and massively multiplayer online role playing games (MMORPGs) (Tychsen et al. 2006; Hitchens and Drachen 2009; Leménager et al. 2014; Shulman 2017). They differ from one another in that board games and LARPs take place in the physical world, while MMORPGs take place in a virtual world. Hence, while LARPs involve overt role playing by the player, MMORPGs may not involve direct acting by the gamer, but instead a type of vicarious acting by means of an avatar. All of the acting is channeled into the avatar, rather than into one's own voice and body. To the extent that people associate themselves to these characters, this practice is a form of role playing. Moreover, it is most likely a vicarious form of proto-acting.

Moving on now to look at the performance types of proto-acting listed in Figure 2, professional storytelling is a common form. Practitioners include not only those individuals who perform at storytelling evenings, but stand-up comedians, who often use auto-dialogue in conveying their personal stories (e.g., a conversation between the comedian and his ex-girlfriend). Impressionism is another interesting form, where an impressionist engages in short bouts of portrayal of multiple characters, doing so in alternation with a return to oneself. Voice actors, such as Mel Blanc, often have to alternate in real-time among numerous characters, such as when Bugs Bunny converses with Daffy Duck in cartoons. Likewise, a ventriloquist undergoes rapid and abrupt alternations between the self and a character through an unusual kind of auto-dialogue with the dummy. In all of these situations, the performers have to rapidly disengage from one character and seamlessly transition to another character, with virtually no carry-over from the previous character.

I would put improvisational acting in this category as well, since there is not the same type of commitment to a character as in dramatic acting, and since the actors tend to engage in short, unscripted bouts of character portrayal no longer than the length of a skit. The same would apply to sketch actors who perform scripted sketches, as these are typically only several minutes in duration. I might even include fashion models in this category, since "striking a pose", either on a runway or during a photo shoot, might be a simple form of character portrayal. Finally, I would put mime theatre here, although character portrayal in pantomime is often indeterminate. Mime theatre is unquestionably a rich example of personal mimicry, but the problem relates to identifying who is the self and who is the character in pantomime theatre, if there indeed is a self. In other words, it is not always clear what is first-person vs. third-person in the mime's actions. Mime theatre often plays out as short segments of actions, punctuated by a return to some baseline condition, be it the self or some baseline character. Interestingly, the historical record indicates that pantomime was one of the earliest forms of theatrical acting, in which a single masked dancer performed multiple roles. In ancient Greece, the pantomimos performed "all the important roles in each story, changing his mask for each one; this was how he derived his name as the one who mimed all (panta) the roles or 'everything in the story'" (Hall 2009, p. 3). This again reflects a key feature of many forms of proto-acting, namely frequent role changes by a single person, in this case accompanied by the ancient prop of the mask.

The last items listed in Figure 2 are religious applications of the proto-acting concept. In possession trance, a person becomes possessed by a god or spirit, often in the context of an initiation rite (Rouget 1985). It would probably be insulting to practitioners of these rites to call this a form of acting. However, it might actually be a form of proto-acting, in which a character takes over the self. Given the fact that possession rituals can be as long as, if not much longer than, dramatic performances, possession trance does not fit the pattern of short bouts of character portrayal that other proposed forms of proto-acting do. However, to the extent that the person undergoes a temporary process of transformation, it does fit the pattern of proto-acting.

Finally, personal prayer in many world religions, especially the Abrahamic religions, takes a form not very different from the one mentioned above of a young girl hosting a tea party with a teddy bear. An interaction is established between the praying person and a non-human-though often personified-partner. While this interaction may be purely monologic, some people report hearing their god speak back to them as well, just as the young girl might imagine the teddy bear making a 
request for more tea. Hence, to the extent that there might be an auto-dialogue taking place in personal prayer, I would classify it as a loose form of proto-acting.

Having explored the contexts and formats of proto-acting, we can now return to the last rows of Table 1 and consider that proto-acting often consists of short bouts of character portrayal, is generally unscripted, and can sometimes make use of props (as in costume parties, children's pretend play, and ventriloquism). To summarize this section, proto-acting is a process of character portrayal that occurs via personal mimicry, generally of familiar contemporaneous people, often involving short bouts of unscripted, prop-less alternation between a character and oneself. There are many exceptions to this definition, and Table 1 and Figure 2 provide a means of showing not only the general nature but also the wide diversity of forms of proto-acting.

\section{The Evolution of Proto-Acting}

In this final section, I would like to consider the implications of proto-acting for human evolution. This is described as a graphic scheme in Figure 3. The top tier of the figure makes an allusion to the fact that theories of language origin come in the two basic varieties of "vocal" and "gestural" models (MacNeilage and Davis 2005; Armstrong and Wilcox 2007; Arbib's 2012). Gestural models posit that gestural symbols evolved earlier than vocal symbols, and that speech was a replacement for a pre-established symbolic system that was mediated by gestures alone. Figure 3 makes reference to the gestural model of language origin proposed by Arbib's (2012). Note that this model is one concerning the timeline of human evolution, rather than a Darwinian model of the functional benefits of language for the human species. Key to Arbib's thinking is the idea that pantomime-in other words, iconic gesturing-was the precursor to a symbolic type of gesturing that Arbib calls "proto-symbol", which is seen as the precursor of language and its capacity to convey narrative. In other words, a system of iconic gesturing through pantomime gave rise to a system of more arbitrary gestures called proto-symbols.

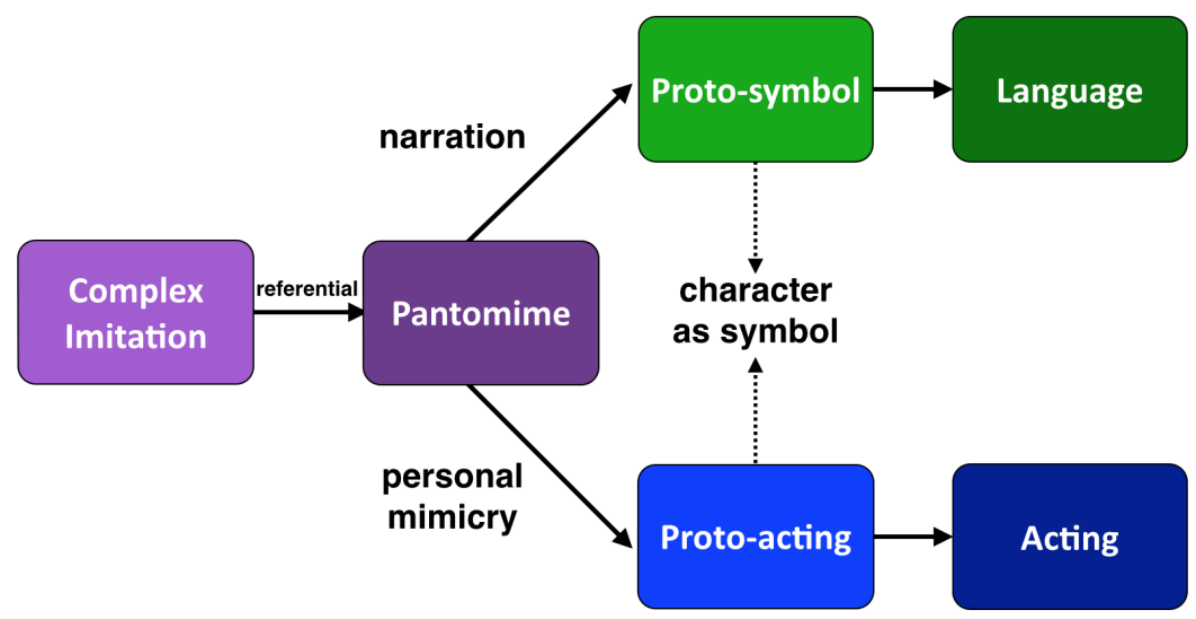

Figure 3. The evolutionary origins of proto-acting. The top tier of the figure represents Arbib's (2012) model of the gestural origins of language. In it, complex imitation predates pantomime, which is the precursor of proto-symbol, which itself is the precursor of language. The lower tier presents my model of the origins of role playing, in which egocentric pantomime leads to proto-acting via the capacity for personal mimicry and pretense. Proto-acting, then, is the precursor of dramatic acting. The interface between the two tiers is the notion that a character is a symbol and therefore that acting is the symbolic creation of a character.

Another feature of Arbib's model shown in the figure is that the capacity for "complex imitation" precedes the evolution of pantomime. It is important to point out that imitation, while iconic, need not be pantomimic at all. What distinguishes pantomime from imitation is that it is communicative, 
whereas imitation need not be (cf Chartrand and Bargh (1999) on the "chameleon effect"). When someone produces a pantomime (whether gestural, vocal, or both), they are communicating with another person, and they are doing so in order to convey information about some other person or object. Hence, the communication process is "triadic" (Arbib et al. 2008): there are two people jointly engaged in communication about some third object. Another way of saying this is that the communication is referential; the content of the communication is about some external object, not about the communicator him- or herself.

While the contrast between vocal and gestural models of language origin is actively debated, I would like to focus my attention here on a topic that is all but ignored in evolutionary psychology, namely the origins of role playing in human evolution. Along these lines, there is a huge literature in psychology devoted to the perceptual process known as theory-of-mind (Nichols and Stich 2003), but there is far less literature about its counterpart production process of role playing. I have argued above that the diverse set of processes that I am calling proto-acting could be reasonably seen as the developmental precursor to the full-fledged dramatic acting that adults (and some children as well) engage in. However, I would now like to take one step back and consider the evolutionary roots of proto-acting itself.

One weakness of Arbib's (2012) evolutionary model of language is that it has a very generic conception of pantomime. In reality, there are multiple types of pantomime (Boyatzis and Watson 1993; O'Reilly 1995; Suddendorf et al. 1999), and the differences between them have important evolutionary and developmental implications that are not discussed in gestural models of language origin. To a first approximation, there is a distinction between egocentric and allocentric pantomimes. The egocentric type is exemplified by the "imaginary object" (IO) pantomime, in which a person performs a transitive action with an imaginary object, such as when someone mimes a tennis serve with an imaginary racquet in one hand and an imaginary ball in the other. The allocentric type is exemplified by the "body-part-as-object" (BPO) pantomime, in which a person uses a body part (typically the hand or its parts) to represent some external object, such as when a person does the "call me" pantomime by using their hand to represent a telephone receiver. Egocentric and allocentric pantomimes require different conceptions of how the body performs actions on objects. Not surprisingly, they show different ontogenetic trajectories, with BPO (a form of object substitution) preceding IO in child development (Boyatzis and Watson 1993; O'Reilly 1995).

Pantomime might be the most fundamental form of pretense (Suddendorf et al. 1999). When miming, a person is pretending to perform some action or pretending that a part of their body is some other object. Miming is not the performance of the action itself, but instead a type of referential communication with other people to convey information about that action to those people. However, in addition to being a form of pretense, pantomime is very often a process of personal mimicry and thus character portrayal. For example, in telling someone about a tennis match that I played with a friend yesterday, I could use pantomime to represent my own serve during the game. However, I could also do it to represent how my friend served the ball, in which case it would be an example of personal mimicry. In fact, much pantomime during human discourse is a mimicry of others, an iconic demonstration of their actions. While such mimicry can be of transitive actions like performing a tennis serve, it can also be of intransitive actions like walking or the expression of emotions. Hence, looking back at Figure 3, I would propose that the type of pantomime that involves egocentric personal mimicry, whether of transitive or intransitive actions, represents the most fundamental form of character portrayal, and by extension the most fundamental form of proto-acting.

I would argue, following Arbib's (2012), that, to the extent that pantomime can be reasonably considered as a precursor to the origins of symbols and language (an idea that is still controversial), it can jointly be considered as a precursor to the origins of personal mimicry, role playing, and acting. While the lower tier in Figure 3 in no way depends upon the veracity of the upper tier, the coupling between the two tiers via pantomime as a joint precursor serves an important conceptual function. It establishes an evolutionary linkage between language and role playing, in other words between a 
system of representation based on third-person narrative description and a system of representation based on first-person embodiment through mimicry. In fact, one could argue that a character is a symbol-where the actor is a stand-in for the real person-and therefore that acting is the symbolic creation of a character through embodiment.

As a final thought about cognitive evolution, I would like to extend this reasoning about role playing to the evolution of the sense of self. Dramaturgical models of social behavior argue that the self is established as the presentation of a character in social situations. In other words, the self is established psychologically only when it can be conceptualized as an other (for example as a person having certain socially-desirable traits). This is the flip side of much contemporary reasoning about the function of mirror neurons in human cognition that theorists like Arbib's (2012) highlight. The mirror-neuron perspective argues that we understand the actions of others via the brain system for self-action; in other words, we understand the other in terms of the self. What I am proposing here is the reverse of mirror-neuron reasoning. Instead of conceptualizing the other in terms of self, I am talking about conceptualizing the self in terms of the other. Personal mimicry, as a mechanism of presenting the self as an other, provides not only a means of having discourse about other people but, more fundamentally, of establishing oneself as an entity distinct from the other. By being able to represent the other, we define the self. To use terminology from Austin (2009), the mirror-neuron system is about seeing the other "egocentrically" (i.e., in terms of oneself), whereas the proto-acting system that I am proposing is about seeing oneself "allocentrically" (i.e., as an entity out there in the world).

\section{Conclusions}

Proto-acting is proposed here as a new concept that occupies the middle ground between the everyday dramaturgical role playing of Goffmanesque models of social behavior and the full-fledged dramatic acting of theatre and cinema. Proto-acting is generally characterized by the use of personal mimicry, whether through quotation in conversation or the impersonation of a celebrity by an impressionist. Proto-acting is the most fundamental form of character portrayal. Compared to dramatic acting, this portrayal is generally short in duration, unscripted, and heavily focused on gesture. I have argued that proto-acting, and role playing more generally, has its evolutionary roots in the personal mimicry that occurs in egocentric pantomime. As such, this highlights the shared origins of role playing and language, as well as the symbolic nature of character portrayal itself.

Acknowledgments: I thank Matthew Berry and Kiran Matharu for helpful suggestions on improving the manuscript. This work was supported by a grant from the Social Sciences and Humanities Research Council (SSHRC) of Canada.

Conflicts of Interest: The author declares no conflict of interest.

\section{References}

Arbib, Michael. 2012. How the Brain Got Language: The Mirror System Hypothesis. Oxford: Oxford University Press.

Arbib, Michael A., Katja Liebal, and Simona Pika. 2008. Primate Vocalization, Gesture, and the Evolution of Human Language. Current Anthropology 49: 1053-76. [CrossRef] [PubMed]

Austin, James H. 2009. Selfless Insight: Zen and the Meditative Transformations of Consciousness. Cambridge: MIT Press.

Armstrong, David F., and Sherman E. Wilcox. 2007. The Gestural Origin of Language. Oxford: Oxford University Press.

Boyatzis, Chris J., and Malcolm W. Watson. 1993. Preschool Children's Symbolic Representation of Objects through Gestures. Child Development 64: 729-35. [CrossRef] [PubMed]

Chartrand, Tanya L., and John A. Bargh. 1999. The Chameleon Effect: The Perception-Behavior Link and Social Interaction. Journal of Personality and Social Psychology 76: 893-910. [CrossRef] [PubMed]

D'Amato, Rik C., and Raymond S. Dean. 1988. Psychodrama Research: Therapy and Theory: A Critical Analysis of an Arrested Modality. Psychology in the Schools 25: 305-14. [CrossRef] 
Goffman, Erving. 1959. The Presentation of Self in Everyday Life. New York: Anchor Books.

Hall, Edith. 2009. Introduction: Pantomime, A Lost Chord of Ancient Culture. In New Directions in Ancient Pantomime. Edited by Edith Hall and Rosie Wyles. Oxford: Oxford University Press, pp. 1-40.

Harris, Paul L. 2000. The Work of the Imagination. Oxford: Blackwell.

Harvey, Graham. 2006. Animism: Respecting the Living World. New York: Columbia University Press.

Hitchens, Michael, and Anders Drachen. 2009. The Many Faces of Role-Playing Games. International Journal of Role-Playing 1: 3-21.

Kemp, Rick. 2012. Embodied Acting: What Neuroscience Tells Us about Performance. London: Routledge.

Kipper, David A., and Timothy D. Ritchie. 2003. The Effectiveness of Psychodramatic Techniques: A Meta-Analysis. Group Dynamics: Theory, Research, and Practice 7: 13-25. [CrossRef]

Konijn, Elly A. 2000. Acting Emotions. Amsterdam: Amsterdam University Press.

Leménager, Tagrid, Julia Dieter, Holger Hill, Anne Koopmann, Iris Reinhard, Madlen Sell, Falk Kiefer, Sabine Vollstädt-Klein, and Karl Mann. 2014. Neurobiological Correlates of Physical Self-Concept and Self-Identification with Avatars in Addicted Players of Massively Multiplayer Online Role-Playing Games (MMORPGs). Addictive Behaviors 39: 1789-97. [CrossRef] [PubMed]

Lillard, Angeline S. 1996. Body or Mind: Children's Categorizing of Pretense. Child Development 67: 1717-34. [CrossRef] [PubMed]

MacNeilage, Peter F., and Barbara L. Davis. 2005. The Frame/Content Theory of Evolution of Speech: A Comparison with a Gestural-Origins Alternative. Interaction Studies 6: 173-99.

Nichols, Shaun, and Stephen Stich. 2003. Mindreading: An Integrated Account of Pretense, Self- Awareness and Understanding Other Minds. Oxford: Oxford University Press.

O'Reilly, Anne W. 1995. Using Representations: Comprehension and Production of Actions with Imagined Objects. Child Development 44: 309-14. [CrossRef]

Rouget, Gilbert. 1985. Music and Trance: A Theory of the Relations between Music and Possession. Chicago: University of Chicago Press.

Schechner, Richard. 2013. Performance Studies: An Introduction, 3rd ed. New York: Routledge.

Shulman, David. 2017. The Presentation of Self in Contemporary Social Life. Thousand Oaks: SAGE Publications.

Suddendorf, Thomas, Claire Fletcher-Flinn, and Leah Johnston. 1999. Pantomime and Theory of Mind. Journal of Genetic Psychology 160: 31-45. [CrossRef]

Tychsen, Anders, Michael Hitchens, Thea Brolund, and Manolya Kavakli. 2006. Live Action Role-Playing Games: Control, Communication, Storytelling, and MMORPG similarities. Games and Culture 1: 252-75. [CrossRef]

Walton, Kendall L. 1990. Mimesis as Make-Believe: On the Foundations of the Representational Arts. Cambridge: Harvard University Press.

Wilshire, Bruce. 1982. Role Playing and Identity: The Limits of Theatre as Metaphor. Bloomington: Indiana University Press.

Zarrilli, Phillip B. 2009. Psychophysical Acting: An Intercultural Approach after Stanislavski. London: Routledge.

(C) 2017 by the author. Licensee MDPI, Basel, Switzerland. This article is an open access article distributed under the terms and conditions of the Creative Commons Attribution (CC BY) license (http://creativecommons.org/licenses/by/4.0/). 